\title{
NÍVEIS DE CÁlCIO E BORO DE GEMAS FLORAIS DE PEREIRA (Pyrus sp.) NO SUL DO BRASIL ${ }^{1}$
}

\author{
VALTAIR VERÍSSIMO ${ }^{2}$, FLAVIO GILBERTO HERTER ${ }^{3}$, ALEXANDRE COUTO RODRIGUES ${ }^{4}$, RENATO TREVISAN ${ }^{4}$, \\ ANDERSON CARLOS MARAFON ${ }^{5}$
}

\begin{abstract}
RESUMO - O objetivo deste trabalho foi determinar os níveis de cálcio (Ca) e boro (B) em gemas florais de pereiras em função do local, cultivar, época e sua distribuição nas gemas. Os experimentos foram conduzidos em duas regiões edafoclimática diferentes no Sul do Brasil: em Pelotas-RS, no Centro de Pesquisa Embrapa Clima Temperado, e em São Joaquim-SC, na Estação Experimental da Empresa de Pesquisa Agropecuária e Extensão Rural de Santa Catarina, durante o outono e inverno de 2000 e 2001. Foram executados três ensaios, envolvendo as cultivares Nijisseiki (Século XX), Kousui e Kieffer. As análises quantitativas de cálcio e boro foram realizadas pelo método adaptado por Freire (1998). As análises químicas possibilitaram verificar que os níveis de cálcio e boro permaneceram praticamente inalterados durante o inverno, nas gemas florais das cultivares Kieffer e Nijisseiki, em Pelotas-RS. A cultivar Nijisseiki possui maior teor de boro nas gemas florais do que a cultivar Kieffer, de melhor adaptação. Do início do outono até o início do inverno, há um incremento nos teores de boro em ambos os locais e cultivares. Na cultivar Nijisseiki, os maiores teores de boro foram detectados na porção basal e mediana da gema floral, enquanto os de cálcio ocorreram na porção basal.
\end{abstract}

Termos para indexação: macronutrientes, micronutrientes, Nijisseiki, Kousui, Kieffer.

\section{LEVELS OF CALCIUM AND BORON ON PEAR FLOWER BUDS (Pyrus sp.) IN SOUTHERN BRAZIL}

ABSTRACT - The objective of this study was to evaluate calcium (Ca) and boron (B) levels, in pear flower buds, on different locations, cultivars, period of the year and portion of bud. The experiments were carried out in two locations with different climatic conditions in Southern Brazil (Embrapa Clima Temperado Research Centre, in Pelotas-RS, and Experimental Station of Empresa de Pesquisa Agropecuária e Extensão Rural de Santa Catarina, in São Joaquim-SC), during the winter of 2000 and 2001. Three experiments were conducted, involving three cultivars, Nijisseiki (XX ${ }^{\text {th }}$ Century), Kousui and Kieffer. The calcium and boron level were determined by the method adapted by Freire (1998). The levels of calcium and boron stayed practically unaltered during the winter in the flower buds of cvs. Kieffer and Nijisseiki, in Pelotas-RS. The cv. Nijisseiki had higher levels of boron than that of cv. Kieffer, more adapted to the region. Since the beginning autumn until early winter there was an increase in levels of boron, in both places and cultivars. The highest boron level was found in the basal and in the medium part of flower buds, whereas the highest levels of calcium was in the basal part.

Index terms: macronutrient, micronutrient, Nijisseiki, Kousui, Kieffer.

\section{INTRODUÇÃO}

O boro (B) é um micronutriente pouco móvel ou de mobilidade intermediaria, não tendo suas funções físiológicas bem esclarecidas até o momento. As principais funções a ele atribuídas são: metabolismo de carboidratos e transporte de açúcares através de membranas (Malavolta et al., 1991; Taiz \& Zieger, 1991), síntese de ácidos nucléicos (DNA e RNA) e fitormônios, formação de parede celular e divisão celular (Dechen et al., 1991). Também é importante na formação de pectina, nos ápices vegetativos, no floema, na formação dos frutos, flores e raízes, na absorção de água e no metabolismo dos glicídios (Basso \& Suzuki, 2001).

Para Larcher (2000), o B é componente enzimático e co-fator, implicando na fotossíntese através do transporte de assimilados e síntese do amido. É um elemento importante para a absorção, transporte e metabolismo de cátions, especialmente o cálcio (Basso \& Suzuki, 2001). Para Brakemeier (1999), o boro ajuda na absorção radicular de cálcio, além de ajudá-lo na sua função. Para Malavolta et al. (1991), o B também está envolvido nas seguintes funções nas plantas: organização e funcionamento das membranas; germinação do grão de pólen e crescimento do tubo polínico; florescimento e expressão sexual; elongação celular e metabolismo dos ácidos nucléicos; metabolismo de fenóis e lignificação (paredes); transporte e metabolismo de auxina e ativação do zinco $(\mathrm{Zn})$.

A deficiência de B acarreta redução na lignificação (menor diferenciação do xilema) e aumento de substâncias pécticas e calose no floema (reduz o transporte de carboidrato no floema), diminui a citocinina nas raízes, além de causar necrose e morte dos pontos de crescimento (Malavolta et al., 1991). Segundo Bonato et al. (1998), em níveis tóxicos, o B causa clorose e necrose da borda das folhas.

Já o cálcio $(\mathrm{Ca})$ é usado na síntese de novas paredes celulares, no fuso mitótico, na atuação normal das membranas, e como mensageiro secundário para um número de respostas das plantas para sinais ambientais e hormonais (Taiz \& Zieger, 1991), e também é indispensável para o desenvolvimento normal do sistema radicular (Basso \& Suzuki, 2001; Taiz \& Zieger, 1991). A sua deficiência resulta em um sistema radicular debilitado e na morte de suas extremidades. Em conseqüência, ocorre prejuízo no desenvolvimento da parte aérea das plantas (Basso \& Suzuki, 2001). Sintomas característicos de deficiência de Ca incluem necrose de ponta e margem de folhas jovens, seguido pela necrose de gemas terminais. Estes sintomas ocorrem em regiões meristemáticas, onde a divisão celular está ocorrendo, e novas paredes são formadas (Taiz \& Zieger, 1991). O cálcio também desempenha outras importantes funções nas plantas, está envolvido na estrutura e estabilidade de membrana celular durante estresse por altas temperaturas, bem como nos períodos de frio (Taiz \& Zieger, 1991), e sua deficiência causa a desintegração de paredes com subseqüente colapso dos tecidos (Bonato et al., 1998).

Entre os tipos de avaliações da nutrição de plantas, a análise foliar é a mais freqüente, mas outros órgãos podem ser utilizados para análises. Resultados de análises de solo são freqüentemente contraditórios, pois, geralmente, não definem a extensão do problema

\footnotetext{
(Trabalho 181/2005). Recebido: 07/11/2005. Aceito para publicação: 23/03/2006.

${ }^{2}$ Eng $^{\circ}$ Agr $^{\circ}$, M.Sc., Doutorando em Agronomia - Fruticultura de Clima Temperado - UFPEL, Campus Universitário, C.P. 354, CEP 96.010-900, Pelotas-RS - Email: valtairverissimo@yahoo.com.br.

${ }^{3}$ Eng $^{\text {O }}$ Agr $^{\circ}$, Dr., Embrapa Clima Temperado, BR 392, Km 78, CP 403, CEP 96001-970, Pelotas-RS - E-mail: herter@cpact.embrapa.br, autor para correspondência.

${ }^{4}$ Eng $^{\circ}$ Agr ${ }^{\circ}$, Dr., Pesquisador RD-CNPq, Embrapa Clima Temperado, BR 392, Km 78, C.P. 403, CEP 96001-970, Pelotas-RS - E-mail: rcale@ufpel.edu.br trevisan@cpact.embrapa.br.

${ }^{5}$ Eng $^{\text {o }}$ Agr $^{\circ}$, M.Sc., Doutorando em Fisiologia Vegetal - IB - UFPEL, Campus Universitário, C.P. 354, CEP 96.010-900, Pelotas-RS

Apoio finaceiro: CAPES, CNPq, JICA e Embrapa Clima Temperado
} 
de desequilíbrios nutricionais. Em muitas espécies decíduas, as plantas apresentam flores antes de folhas e, neste caso, um diagnóstico mais cedo pode ser obtido através de análise de flores (Lucena, 1997). Quando se quer identificar um distúrbio nutricional em período que não há presença de folhas, as gemas podem ser uma boa alternativa, especialmente quando o desequilíbrio se expressa nas gemas, como é o caso do abortamento de gemas florais, comum em pereiras no Sul do Brasil, e que limita a expansão da cultura.

O B e o Ca são de grande importância para o desenvolvimento dos vegetais. É possível que estes dois nutrientes tenham papel relevante no abortamento de gemas florais em pereira, nas condições edafoclimática do Sul do Brasil. Um maior conhecimento das concentrações desses nutrientes durante o ciclo anual pode contribuir para o maior entendimento dos processos fisiológicos que ocorrem nas plantas durante o outono e o inverno.

O objetivo deste trabalho foi determinar os níveis de cálcio e boro em gemas florais de pereira de diferentes cultivares, épocas e porção da gema em duas regiões edafoclimáticas no Sul do Brasil.

\section{MATERIALEMÉTODOS}

Os experimentos foram conduzidos em dois locais no Sul do Brasil. Em Pelotas-RS, as plantas de pereira das cvs. Nijisseiki, Kieffer e Kousui estavam localizadas em pomar da Embrapa Clima Temperado $\left(52^{\circ} 21^{\prime} \mathrm{W}\right.$ e $\left.31^{\circ} 52^{\prime \prime} \mathrm{S}\right)$, a $224 \mathrm{~m}$ de altitude, com precipitação média anual de $1.582 \mathrm{~mm}$, temperatura média anual de $18,4^{\circ} \mathrm{C}$ e média de 550 horas de frio $\left(\leq 7,2^{\circ} \mathrm{C}\right)$, de maio a setembro; com solo do tipo LUVISSOLO HIPOCRÔMICO Órtico Típico, argiloso, pouco profundo e geralmente mal drenado. Em São Joaquim-SC, utilizou-se de plantas de pereira de pomar da Estação Experimental da Empresa de Pesquisa Agropecuária e Extensão Rural de Santa Catarina (49 55' 56"'W e $28^{\circ} 17^{\prime} 39^{\prime \prime}$ S), localizada a $1.415 \mathrm{~m}$ de altitude, com temperatura média anual de $13,4^{\circ} \mathrm{C}$; precipitação média anual de $1.713 \mathrm{~mm}, 917$ horas de frio $\leq 7,2^{\circ} \mathrm{C}$ (maio a setembro). $\mathrm{O}$ solo local é CAMBISSOLO HÚMICO Álico, argiloso e moderadamente drenado.

Os tratamentos fitossanitários e as práticas culturais utilizados foram os normalmente indicados para a cultura. Foram utilizadas nos experimentos plantas adultas (pomares com 8-10 anos), em produção, e enxertadas sob Pyrus calleryana.

As gemas coletadas das plantas foram levadas ao laboratório, onde foram seccionadas na base (padronizadas), para tornar possíveis as comparações. Em seguida, foram colocadas em estufa a $65^{\circ} \mathrm{C}$ até peso constante. De cada amostra tomaram-se cerca de $2 \mathrm{~g}$ de matéria seca para a análise química. As análises de Ca e B foram realizadas no laboratório da Embrapa Clima Temperado, de acordo com o método adaptado por Freire (1998).

\section{Experimentos}

Experimento 1 Foram quantificados os teores de $\mathrm{Ca}$ e B em gemas florais das cultivares Nijisseiki (uma cultivar com sérios problemas de abortamento) e Kieffer (que praticamente não apresenta problemas), em Pelotas-RS. As gemas foram coletadas em quatro épocas, entre meados e fim do inverno. O experimento foi conduzido em esquema fatorial 2 x 4, com os fatores Cultivar (Nijisseiki e Kieffer) e Época de coleta (11-08, 24-08, 08-09 e 21-09-2000), em delineamento inteiramente casualizado, com 4 repetições. Foi feita a análise de variância e, para a comparação das médias, utilizou-se do teste de Duncan, a 5\% de probabilidade.

Experimento 2 Foram quantificados os teores de $\mathrm{Ca}$ e B em gemas florais das cultivares Nijisseiki e Kousui, em dois locais: PelotasRS, local onde as plantas apresentam altos níveis de abortamento e São Joaquim-SC, onde as plantas apresentam abortamento reduzido. As gemas foram coletadas em duas épocas: início do outono (10-04-2001) e início do inverno (28-06-2001). O delineamento experimental foi o inteiramente casualizado, com 7 repetições. O delineamento foi um

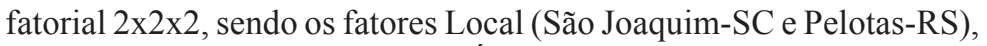
Cultivar (Nijisseiki e Kousui) e Época (início do outono e início do inverno). Em relação aos locais, foi feito teste de homogeneidade de variância, sendo que a mesma não foi significativa. Foi feita a análise de variância e, para comparação de médias, utilizou-se do teste de Duncan, a $5 \%$ de probabilidade.

Experimento 3 Foram quantificados os teores de $\mathrm{Ca}$ e B em diferentes porções das gemas. Para isso, cada gema foi seccionada radialmente em terço apical, mediano e basal. As gemas foram coletadas em Pelotas-RS, no fim do inverno (31-08-2000). Neste experimento, as gemas foram seccionadas em duas porções (apical e basal), e em três porções (apical, mediana e basal). $\mathrm{O}$ experimento foi realizado em esquema inteiramente casualizado, com 6 repetições. Foi feita a análise de variância e, para comparação de médias, utilizou-se do teste Duncan, a $5 \%$ de probabilidade.

\section{RESULTADOS E DISCUSSÃO}

\section{Experimento 1}

Neste experimento, os níveis de Ca e B em gemas florais de pereira de duas cultivares, em Pelotas-RS, não diferiram entre as quatro épocas de coleta (meados a fim do inverno), com exceção de apenas uma data, referente à segunda coleta (24-08), na qual a cv. Kieffer apresentou teor maior de $\mathrm{Ca}$ (Tabela 1). Assim, os níveis de Ca e B permaneceram praticamente inalterados durante o inverno, em ambas as cultivares.

TABELA 1 - Níveis de cálcio e boro em gemas florais de duas cultivares de pereira em quatro épocas de coleta, no inverno de 2000 , em Pelotas-RS.

\begin{tabular}{ccccc}
\hline & \multicolumn{2}{c}{ Ca $\left(\mathbf{g} \cdot \mathbf{k g}^{-1}\right)$} & \multicolumn{2}{c}{ B $\left(\mathbf{m g} \cdot \mathbf{k g}^{-1}\right)$} \\
\cline { 2 - 5 } Época & Kieffer & Nijisseiki & Kieffer & Nijisseiki \\
\hline $11-08-00$ & $18,3 \mathrm{bA}$ & $16,2 \mathrm{aA}$ & $105,33 \mathrm{aB}$ & $149,67 \mathrm{aA}$ \\
$24-08-00$ & $22,6 \mathrm{aA}$ & $16,6 \mathrm{aB}$ & $97,66 \mathrm{aB}$ & $127,00 \mathrm{aA}$ \\
$08-09-00$ & $16,3 \mathrm{bA}$ & $14,5 \mathrm{aA}$ & $98,66 \mathrm{aB}$ & $145,00 \mathrm{aA}$ \\
$21-09-00$ & $15,5 \mathrm{bA}$ & $14,4 \mathrm{aA}$ & $97,33 \mathrm{aB}$ & $144,00 \mathrm{aA}$ \\
\hline Média & $18,2 \mathrm{~A}$ & $15,4 \mathrm{~A}$ & $99,75 \mathrm{~B}$ & $135,5 \mathrm{~A}$ \\
\hline
\end{tabular}

Médias seguidas pela mesma letra, minúscula na coluna e maiúscula na linha, não diferem entre si, pelo teste Duncan, a 5\% de probabilidade.

Na comparação entre cultivares, a 'Nijisseiki' teve, nas quatro épocas analisadas, maior teor de B que a 'Kieffer', cultivar melhor adaptada às condições climáticas do Sul do Brasil. Os teores de cálcio entre as cultivares foram similares (Tabela 1).

Interpretando os teores de cálcio e boro encontrados em gemas florais, com uma tabela de interpretação de análise foliar (Tabela 2), os teores de cálcio encontrados em gemas florais se classificam na faixa 'Normal' e, eventualmente, 'Acima do Normal'. Já os teores de B encontrados em gemas foram muito altos nas duas cultivares, enquadrando-se na faixa 'Acima do Normal' e, geralmente em 'Excesso', na cv. Nijisseiki, a qual tem apresentado altos níveis de abortamento de gemas florais. Esses resultados poderão servir de base para testar a hipótese a fim de verificar se esse nutriente está presente em níveis

TABELA 2 - Concentração de nutrientes minerais, cálcio e boro, para interpretação em folha de pereira.

\begin{tabular}{cccccc}
\hline Elemento & Insuficiente & Abaixo do Normal & Normal & Acima do Normal & Excesso \\
\hline Cálcio $\left(\mathrm{g} \cdot \mathrm{kg}^{-1}\right)$ & $<8,0$ & $8-10,9$ & $11-17$ & $>17,0$ \\
Boro $\left(\mathrm{mg} \cdot \mathrm{kg}^{-1}\right)$ & $<20$ & $20-25$ & $25-50$ & $51-140$ & $>140$ \\
\hline
\end{tabular}

Fonte: Basso \& Suzuki (2001); Fachinello et al. (1996) 


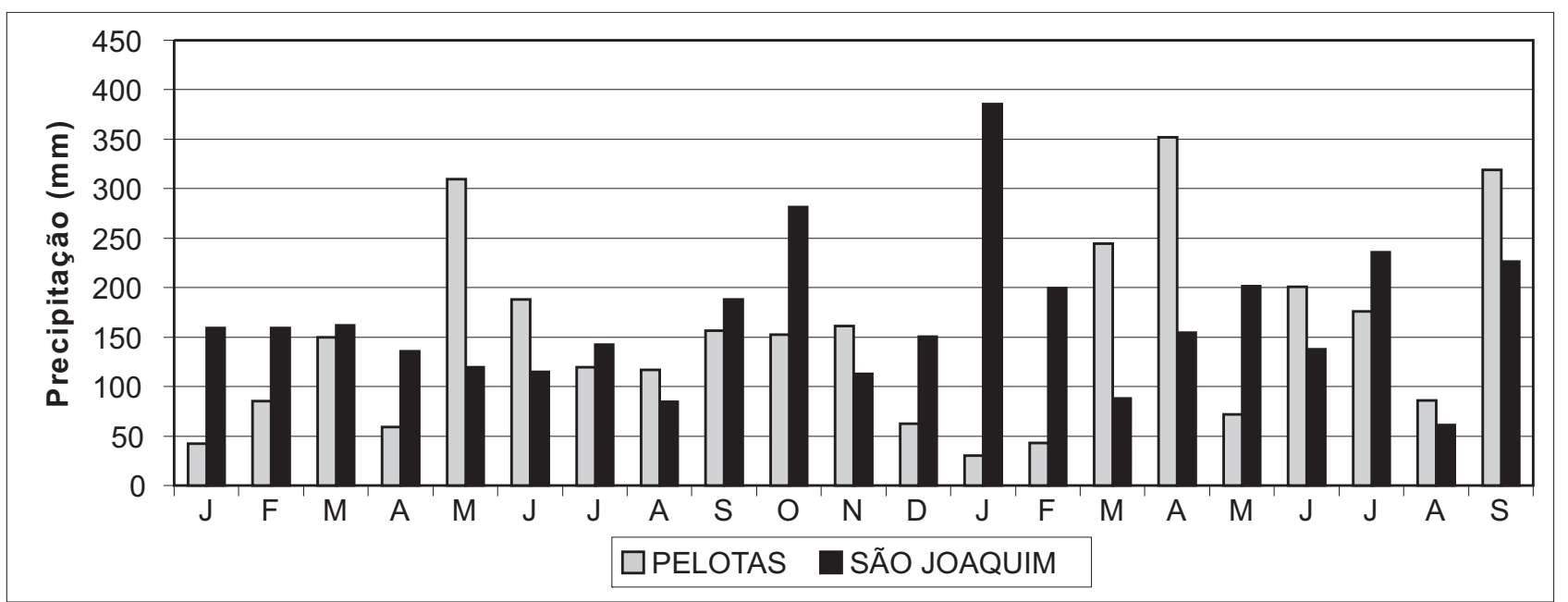

FIGURA 1 - Precipitação pluviométrica (mm) observada em Pelotas e São Joaquim, para o período de janeiro de 2000 a setembro 2001 . Pelotas-RS, 2001.

tóxicos, prejudicando o bom desenvolvimento das gemas.

São poucos os estudos de quantificação de macro e micronutrientes em gemas florais de frutíferas. Os níveis de Ca e B obtidos por Gispert et al. (1990), na Espanha, em gemas dormentes de pereira, variaram de 18,4 a $56 \mathrm{mg} \cdot \mathrm{kg}^{-1}$ para o boro, teores muito abaixo dos quantificados neste trabalho, e de 17 a 44,5 g. $\mathrm{kg}^{-1}$ para o cálcio. Nachtigall (2000), estudando nutrientes em gemas de macieira, coletadas 30 dias antes da brotação, encontrou teores médios de B de $65 \mathrm{mg} \cdot \mathrm{kg}^{-1}$ para a cv. Gala e 58,25 mg.kg-1 para a cv. Fuji. O mesmo autor verificou que os níveis nutricionais nas gemas não são influenciados pelo tipo de estrutura (ramo terminal e esporões).

Segundo Larcher (2000), os limites de B em plantas variam de 8 a $200 \mathrm{mg} \cdot \mathrm{kg}^{-1}$ e as necessidades de 10 a 40 mg. $\mathrm{kg}^{-1}$ de matéria seca. Raven et al. (1996) relatam que as concentrações de B em plantas sadias variam de 5 a $75 \mathrm{mg} \cdot \mathrm{kg}^{-1}$. O limite para toxicidade por B é muito pequeno, sendo que, para macieira, pode haver toxicidade com teores de $70 \mathrm{mg} . \mathrm{kg}$ ${ }^{1}$, e em pessegueiro a $80 \mathrm{mg} \cdot \mathrm{kg}^{-1}$ (Faust, 1989). De acordo com Bonato et al. (1998), o limite de deficiência e o de toxicidade de B são muito próximos e variam entre as espécies. Em plantas tropicais, esse limite entre deficiência e toxicidade é normalmente maior.

\section{Experimento 2}

Na comparação entre locais em duas épocas (início do outono e início do inverno), em Pelotas, a cv. Nijisseiki teve maior teor de Ca no início do outono em relação a São Joaquim. No entanto, verifica-se que, em Pelotas, no início do inverno, os teores caíram de 16,4 g. $\mathrm{kg}^{-1}$ para 11,9 g.kg-1. Na cv. Kousui, em São Joaquim, houve maior teor de cálcio que em Pelotas, no início do outono (Tabela 3).

Comparando-se as cultivares em cada local, verifica-se que, em Pelotas, no início do outono, a cv. Nijisseiki possui maior teor de $\mathrm{Ca}$ comparado a 'Kousui'. Em São Joaquim, no início do outono, é a 'Kousui', que possui mais Ca que a 'Nijisseiki' (Tabela 3).

Na comparação entre locais, para o boro, verifica-se que, para

TABELA 3 - Níveis de cálcio e boro em gemas florais de duas cultivares de pereira em dois locais no Sul do Brasil, em duas épocas de coleta, no ano de 2001.

\begin{tabular}{lcccc}
\hline \multirow{2}{*}{ Cultivar } & \multicolumn{2}{c}{$\begin{array}{c}\text { São Joaquim-SC } \\
\text { Início } \\
\text { outono }\end{array}$} & $\begin{array}{c}\text { Início } \\
\text { Inverno }\end{array}$ & \multicolumn{2}{c}{$\begin{array}{c}\text { Pelotas-RS } \\
\text { Início } \\
\text { outono }\end{array}$} & $\begin{array}{c}\text { Início } \\
\text { Inverno }\end{array}$ \\
\hline \multirow{3}{*}{ Nijisseiki } & \multicolumn{2}{c}{$\mathrm{Ca}\left(\mathrm{g} \cdot \mathrm{kg}^{-1}\right)$} & \multicolumn{2}{c}{$\mathrm{Ca}\left(\mathrm{g} \cdot \mathrm{kg}^{-1}\right)$} \\
\cline { 2 - 5 } Kousui & $10,6 \mathrm{bB}$ & $11,3 \mathrm{aA}$ & $16,4 \mathrm{aA}$ & $11,9 \mathrm{aA}$ \\
& $14,3 \mathrm{aA}$ & $12,4 \mathrm{aA}$ & $11,0 \mathrm{bB}$ & $12,5 \mathrm{aA}$ \\
\hline \multirow{2}{*}{ Nijisseiki } & \multicolumn{2}{c}{$\mathrm{B}\left(\mathrm{mg} \cdot \mathrm{kg}^{-1}\right)$} & \multicolumn{2}{c}{$\mathrm{B}\left(\mathrm{mg}^{-1} \mathrm{~kg}^{-1}\right)$} \\
\cline { 2 - 5 } Kousui & $47,86 \mathrm{bB}$ & $51,43 \mathrm{bB}$ & $64,71 \mathrm{aA}$ & $75,00 \mathrm{aA}$ \\
\hline
\end{tabular}

Médias seguidas pela mesma letra, minúscula na coluna e maiúscula na linha, não diferem entre si, pelo teste Duncan, a $5 \%$ de probabilidade. a 'Nijisseiki', os maiores teores foram encontrados nas gemas coletadas em Pelotas, tanto no início do outono como do inverno. Já, na 'Kousui', os maiores teores de boro foram encontrados nas gemas coletadas em São Joaquim (Tabela 3).

Comprando-se as cultivares para cada local, em São Joaquim, a cv. Kousui apresentou maior teor de B que a cv. Nijisseiki nas duas épocas de coleta. Já em Pelotas, ocorreu o contrário, a cv. Nijisseiki, que teve maior teor de B que a 'Kousui'. Observou-se também que, do início do outono até o início do inverno, há um incremento nos teores de B, em ambos os locais e cultivares (Tabela 3 ).

A quantidade de provisão de nutrientes para a raiz e parte aérea é dependente da taxa de água, bem como da concentração dos nutrientes na solução do solo. Após a absorção, os nutrientes minerais são translocados para várias partes da planta para utilização em importantes funções biológicas (Taiz \& Zieger, 1991). Portanto, as quantidades de precipitação são importantes quando se trata de nutrientes minerais, e, neste caso, há variações quanto à distribuição de chuvas nos locais analisados (Figura 1). A região de Pelotas apresentou uma distribuição irregular na precipitação pluviométrica, principalmente no verão e outono.

Com base nesses experimentos, é possível que a ocorrência de abortamento não deva estar relacionada à deficiência de boro, pois os teores são elevados em gemas florais de diferentes cultivares, locais e épocas de coleta, além do que, os maiores teores de boro foram encontrados em Pelotas-RS, na cv. Nijisseiki, a qual tem apresentado níveis de abortamento extremamente alto, geralmente em torno de $90 \%$ das gemas.

\section{Experimento 3}

Os dados relativos à secção de gema em duas partes (apical e basal) demonstraram que o maior teor de Ca se encontra na metade inferior da gema, com cerca de $70 \%$ do conteúdo total. Quanto ao B, os teores também foram maiores na porção inferior da gema, porém com menor variação com relação à porção apical (Tabela 4).

TABELA 4 - Teores médios de cálcio e boro em gemas florais de pereira, cultivar Nijisseiki, em diferentes porções de gema (gemas seccionadas em 2 e 3 porções), coletadas no fim do inverno de 2000, em Pelotas-RS.

\begin{tabular}{|c|c|c|}
\hline 2 PORÇÕES & $\mathrm{Ca}\left(\mathrm{g} . \mathrm{kg}^{-1}\right)$ & B (mg.kg-1) \\
\hline Apical & $6,70 \mathrm{~b}$ & $141,67 \mathrm{~b}$ \\
\hline Basal & $18,60 \mathrm{a}$ & $158,33 \mathrm{a}$ \\
\hline 3 PORÇÕES & $\mathrm{Ca}\left(\mathrm{g} . \mathrm{kg}^{-1}\right)$ & B (mg.kg $\left.{ }^{-1}\right)$ \\
\hline Apical & $6,00 \mathrm{~b}$ & $112,67 \mathrm{~b}$ \\
\hline Mediana & $9,30 \mathrm{~b}$ & $165,00 \mathrm{a}$ \\
\hline Basal & $21,20 \mathrm{a}$ & $140,67 \mathrm{a}$ \\
\hline
\end{tabular}

Médias seguidas pela mesma letra, na coluna, não diferem entre si, pelo teste Duncan, a 5\% de probabilidade. 
Quando se dividiram as gemas em três porções, o teor de Ca no terço inferior foi, na média, superior aos outros dois terços acima, sendo inclusive superior à soma dos teores do terço mediano e superior. Verificou-se também que a distribuição do B foi maior no terço mediano e basal (Tabela 4). Os teores obtidos para a cv. Nijisseiki, em Pelotas, no fim do inverno de 2000, são extremamente altos, situando-se na faixa 'Acima do Normal' e em 'Excesso'.

Um dos objetivos de quantificar os teores macro e micronutrientes em nível de gemas está na possibilidade de utilizar essas informações no esclarecimento de distúrbios fisiológicos, como o abortamento de gemas florais. Suspeita-se que o boro possa estar envolvido no distúrbio (Verissimo, 2002). Assim, em estudos futuros poderá ser testado mais precisamente o efeito da aplicação de diferentes doses de cálcio e boro em plantas de pereira e, assim, verificar os teores nas gemas e o efeito no abortamento de gemas florais. Nestes experimentos e através da revisão de literatura, observou-se que a ocorrência de abortamento não deve estar relacionado à deficiência de $\mathrm{B}$.

\section{CONCLUSÕES}

1. Os níveis de cálcio e boro permaneceram praticamente inalterados durante o inverno nas gemas florais das cultivares Kieffer e Nijisseiki, em Pelotas-RS.

2. A cultivar Nijisseiki possui maior teor de boro nas gemas florais do que a cultivar Kieffer, de melhor adaptação.

3. Do início do outono até o início do inverno, há um incremento nos teores de boro em ambos os locais e cultivares testados.

4. Na cultivar Nijisseiki, os maiores teores de boro foram detectados na porção basal e mediana da gema floral, enquanto os de cálcio ocorreram na porção basal.

\section{AGRADECIMENTOS}

Ao Laboratório de Nutrição Vegetal da Embrapa Clima Temperado, em especial ao Dr. Claudio José da Silva Freire, pela realização das análises químicas do material vegetal. Aos pesquisadores Dr. Darcy Camelatto, Dr ${ }^{\mathrm{a}}$ Maria do Carmo Bassols Raseira, Dr. Clori Basso, Dr. Carlos Reisser Jr. e Dra Márcia Wulff Schuch, pelas contribuições prestadas à realização do trabalho. Agradecemos também à Estação Experimental da Empresa de Pesquisa Agropecuária e Extensão Rural de Santa Catarina (EPAGRI), pelo apoio e colaboração.

\section{REFERÊNCIAS}

BASSO, C.; SUZUKI, A. Solos e nutrição. In: EPAGRI (Ed.). Nashi, a pêra japonesa. Florianópolis: Epagri/Jica, 2001. cap.4, p.139-160.
BONATO, C. M.; RUBIN FILHO, C. J.; MELGES, E.; SANTOS, V. Nutrição mineral de plantas. Maringá: Universidade Estadual do Maringá, 137p. 1998.

BRAKEMEIER, C. Adubação foliar: a complementação nutricional da macieira. Jornal da Fruta, Lajes, p.7, 1999.

DECHEN, A. R.; HAAG, H. P.; CARMELLO, Q. A. C. Funções dos micronutrientes nas plantas. In: FERREIRA, M. E.; CRUZ, M. C. P. (Ed.). Micronutrientes na agricultura. Piracicaba: Potafos-CNPq, 1991. cap. 3, p.65-78.

FACHINELLO, J. C.; NACHTIGAL J. C.; KERSTEN, E. Fruticultura: fundamentos e práticas. Pelotas: Editora UFPEL, 1996.311p.

FAUST, M. Physiology of temperate zone fruit tress. New York: J. Wiley, 1989.338p.

FREIRE, C. J. S. Manual de métodos de análises de tecido vegetal, solo e calcário. Pelotas: Embrapa-CPACT, 1998. 208p.

GISPERT, M.; RECAS, E.; MONTESINOS, E.; VILARDELL, P. Evaluación de las perdidas producidas por la anulación de yemas florales en peral, en relación a su estado nutricional. In: CONGRESO IBÉRICO DE CIÊNCIAS HORTÍCOLAS,1., 1990. Lisboa. Actas... p.67-72.

LARCHER, W. A utilização dos elementos minerais. In: LARCHER, W. (Ed.). Ecofisiologia vegetal. São Carlos: Editora RiMa, 2000. cap.3, p.183-230.

LUCENA, J. J. Methods of diagnosis of mineral nutrition of plants: a critical review. Madrid: Dpto. Química agrícola, Universidade Autônoma,1997.p.179-192.

MALAVOLTA, E.; BOARETTO, A. E.; PAULINO, V. T. Micronutrientes - Uma visão geral. In: FERREIRA, M. E.; CRUZ, M. C. P. (Ed.). Micronutrientes na agricultura. Piracicaba: Potafos-CNPq, 1991. cap.1, p.1-33.

NACHTIGALL, G. R. Estruturas floríferas na qualidade de maçãs, cultivares Gala e Fugi, 2000. 58f. Dissertação (Mestrado em Agronomia). Faculdade de Agronomia Eliseu Maciel, Universidade Federal de Pelotas, Pelotas, 2000.

RAVEN, P. H.; EVERT, R. F.; EICHORN, S. E. Nutrição Vegetal e Solos. In: RAVEN, P. H.; EVERT, R. F.; EICHORN, S. E. Biologia vegetal. 5. ed. Rio de Janeiro: Guanabara Koogan S.A., 1996. cap.27, p.552573.

TAIZ, L.; ZIEGER, E. Mineral nutrition. In: TAIZ, L.; ZIEGER, E. Plant physiology. Califórnia: The Benjamin/Cummings Publishing Company, 1991. cap.5, p.100-119.

VERISSIMO, V. Caracterização de parâmetros físicos, químicos e morfológicos de gemas florais de pereira no Sul do Brasil, e sua relação com o abortamento. 2002. 58f. Dissertação (Mestrado em Agronomia) - Faculdade de Agronomia Eliseu Maciel, Universidade Federal de Pelotas, Pelotas, 2002. 